\title{
Simulate the effect of integral burnable absorber on the neutronic characteristics of a PWR assembly
}

\author{
A. Abdelghafar Galahom ${ }^{1}$ \\ 1 Higher Technological Institute, 10th of Ramadan City, 228, Egypt \\ Corresponding author: A. Abdelghafar Galahom (Galhom_20102000@yahoo.com)
}

Academic editor: Yury Kazansky • Received 6 October 2018 Accepted 30 November 2018 Published 13 December 2018

Citation: Galahom AA (2018) Simulate the effect of integral burnable absorber on the neutronic characteristics of a PWR assembly. Nuclear Energy and Technology 4(4): 287-293. https://doi.org/10.3897/nucet.4.30379

\begin{abstract}
This article examines the effect of an integral burnable absorber (IBA) on the neutronic characteristics of Pressurized Water Reactor (PWR) to provide possible improvements for the fuel management. MCNPX code was used to design a three dimensional model for PWR assembly. The designed model has been validated by comparing the output data with a previously published data. MCNPX code was used to analyze the radial thermal neutron flux and the radial power distribution through PWR assembly with and without IBA. Gadolinium is burnable absorber material that was used in the IBA rods. The gadolinium element suppressed the power in the regions where they were distributed. The existence of IBA rods has a large effect on the $K_{\text {inf }}$ This effect decreases gradually with burnup due to the degradation of gadolinium. The gadolinium isotopes degradation was analyzed with burnup. Different numbers of IBA rods were investigated to optimize the suitable number that can be used in the PWR assembly. The gadolinium effect on the concentration of ${ }^{135} \mathrm{Xe}$ and ${ }^{149} \mathrm{Sm}$ resulting from the fission process was analyzed.
\end{abstract}

\section{Keywords}

PWR; IBAs; MCNPX code; $\mathrm{Gd}_{2} \mathrm{O}_{3}$; Power; Thermal neutron flux

\section{Introduction}

Simulating the effect of IBAs on the neutronic characteristics of PWR using MCNPX code plays an important role in the design and evaluation of nuclear systems. PWR is considered one of the most common types of nuclear reactors. Currently, there are about 269 PWRs are in use for power generation and several hundred more employed for naval propulsion (Huda et al. 2011). The high capital cost of large nuclear reactors appears to be the most limiting issues hindering the easy deployment today. In addition to the capital cost, large power additions may endanger the grid operation and stability in many areas (Karahan
2010). Core management with burnable absorber (BAs) enables uniform, but slow control of reactivity and power distribution. BA is a strong neutron absorber that is converted into a less neutron absorbent nuclide after capturing a neutron. One commonly used BA scheme in a PWR is by mixing $\mathrm{Gd}_{2} \mathrm{O}_{3}$ to $\mathrm{UO}_{2}$ fuels. This technique reduces the power density of the oxide fuels. $\mathrm{Gd}_{2} \mathrm{O}_{3}$ replaces the fuel itself and the fuel mass are reduced (Yahya et al. 2014). The use of BAs needs to be increased for a safe and economical operation of a PWR. Two general types of burnable absorbers (BAs) are used with PWR fuel: integral burnable absorbers (IBAs) and burnable poison rods (BPRs). IBAs are non-removable neutron absorbing 
materials used as components of a fuel assembly. BPRs are rods that contain neutron absorbing materials that can be inserted into PWR assembly guide tubes. Both types of BAs can be used to control core reactivity, local power peaking and optimize fuel utilization. BPRs are designed to function during the first cycle of irradiation of a fresh and unirradiated fuel assembly. After one cycle of irradiation, the BPRs are typically removed from the fuel assembly allowing primary coolant to occupy the guide tube volume displaced by the BPRs. In the case of IBAs, the rods remain in the fuel assembly throughout its lifetime and usually account for a small reactivity penalty at the end of life. This is due to the incomplete consumption of the neutron absorber material (O'Leary and Pitts 2000).

Several different types of IBAs have been used in commercial nuclear fuel assembly designs. All of the various designs are similar in that they contain thermal neutron absorbing material as an integral, non-removable part of the fuel assembly. Variations in the IBA material, composition, placement within rods and rod configurations exist among current PWR fuel assembly designs. These IBA

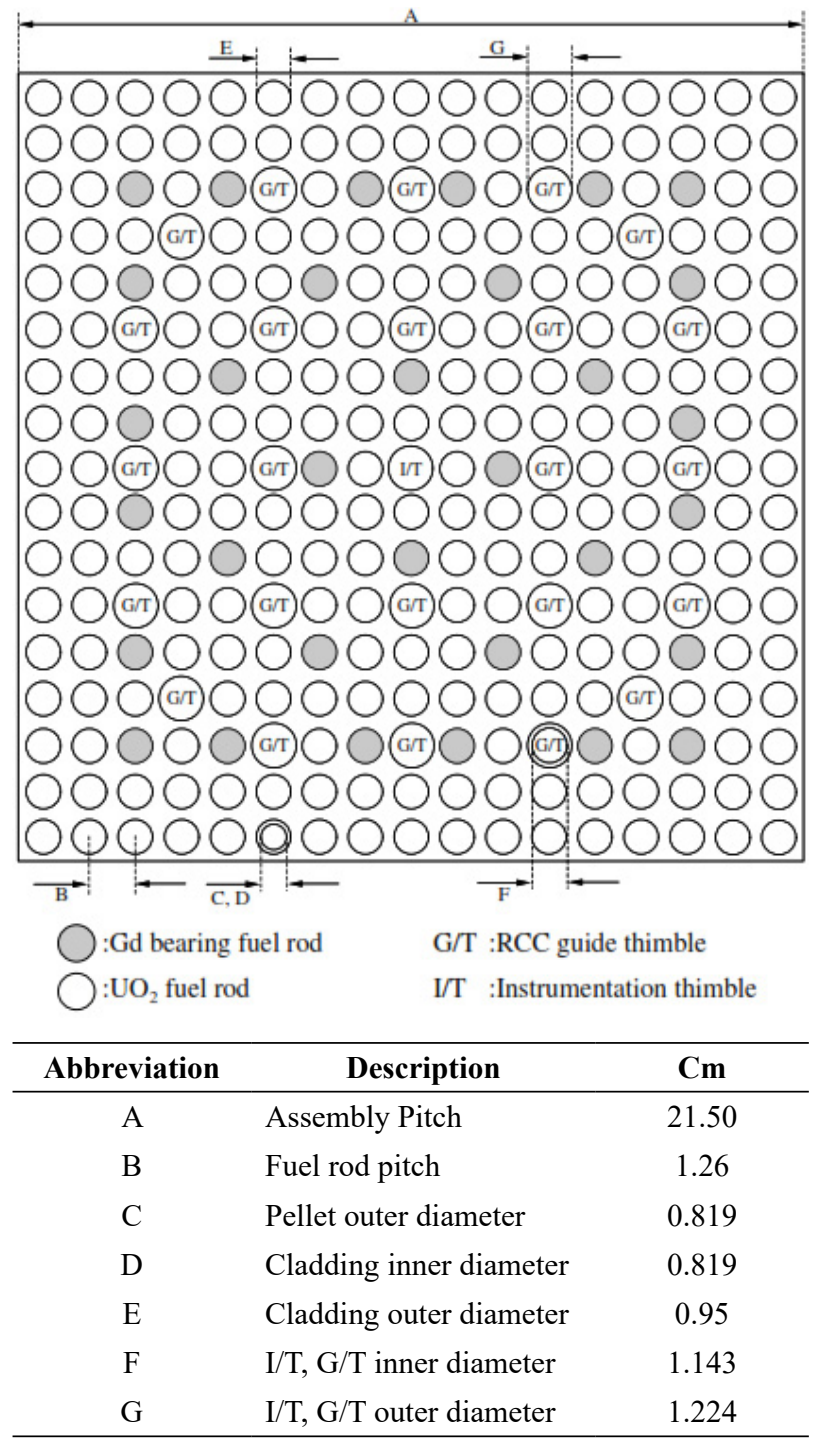

Figure 1. Geometrical configuration of $\mathrm{PWR} \mathrm{UO}_{2}$ assembly characteristics may also be varied in combination with the initial fuel assembly enrichment and core location to achieve core operation and fuel management goals (Sanders and Wagner 2002).

The IBA types that have been widely used in United State PWRs include Westinghouse assembly designs with integral fuel burnable absorber IFBA rods, Combustion Engineering (CE) and Siemens assembly design with $\mathrm{UO}_{2}+\mathrm{Gd}_{2} \mathrm{O}_{3}$ rods, $\mathrm{CE}$ assembly designs with $\mathrm{UO}_{2}+\mathrm{Er}_{2} \mathrm{O}_{3}$ rods, and $\mathrm{CE}$ assembly designs with $\mathrm{Al}_{2} \mathrm{O}_{3}-\mathrm{B}_{4} \mathrm{C}$ rods ( $\mathrm{Ga}-$ lahom 2016).

The presence of burnable absorbers during depletion hardens the neutron spectrum, resulting in lower ${ }^{235} \mathrm{U}$ depletion and higher production of fissile plutonium isotopes. The enhanced plutonium production has the effect of increasing the reactivity of the fuel at discharge. Consequently, an assembly exposed to burnable absorbers may have a slightly higher reactivity for a given burnup than an assembly that has not been exposed to burnable absorbers (Sanders and Wagner 2002). The following sections provide an overview of the calculation approach used for this study. In this work a three dimensional PWR assembly was designed using MCNPX code. This model was used to investigate the effect of IBA $\left(\mathrm{UO}_{2}+\mathrm{Gd}_{2} \mathrm{O}_{3}\right)$ on the reactivity and the power as a function of Effective Full Power Day (EFPD). Different numbers of IBAs rods were investigated to obtain a suitable number.

\section{Reference Benchmark PWR Model}

A typical Westinghouse PWR core was selected as a core reference. The number of fuel assembly in the core is 193, rated $3358 \mathrm{MWth}$. Each assembly contains $17 \times 17$ array of pins. This assembly has 24 guide tubes, 1 instrumentation tube and 264 fuel pins. Due to the symmetry of the PWR assemblies, one assembly has been simulated using MCNPX. The geometrical description and configuration of the assembly geometry are given in Fig.1. The PWR assembly is fueled with uranium dioxide. This fuel is burned for 1800 days with a specific power of $37.33 \mathrm{MW} /$ MTHM. The detailed parameters of this fuel assembly are described in Table 1. (Fridman and Kliem 2011).

Table 1. Benchmark problem design parameters

\begin{tabular}{lc}
\hline Operating parameter & Value \\
\hline Assembly array & $17 \times 17$ \\
Number of fuel rods per assembly & 264 \\
Number of Guide Tubes (GT) & 24 \\
Number of Instrumentation Tubes (IT) & 1 \\
Cladding material & Zircaloy \\
Active fuel height & $366 \mathrm{~cm}$ \\
Fuel Temperature & $900 \mathrm{~K}$ \\
Cladding Temperature & $581 \mathrm{~K}$ \\
Coolant Temperature & $581 \mathrm{~K}$ \\
\hline
\end{tabular}




\section{Calculation tool}

In this work, the fuel assembly level calculations were performed with the well-known MCNPX code. Monte Carlo radiation transport computer code MCNPX is based on CINDER90 and Monte Burns for its depletion/ burnup capabilities. MCNPX is a Fortran90 Monte Carlo radiation transport computer code. The new capabilities of the MCNPX 2.6.0 version are used to analyze the effect of IBA on the neutronic characteristics of PWR. MCNPX is capable of simulating 34 particle types and more than 2000 heavy ions at low as well as very high energies (Galahom et al. 2015). This code is a general purpose, generalized-geometry, continuous energy, time-dependent, coupled neutron/photon /electron Monte Carlo transport code that solves transport problems in an arbitrary three dimensional geometry. Quantities that may be tallied include particle or energy current and flux across a surface, flux or energy deposition averaged over a volume, and flux at a point for a point detector. A wide variety of multipliers are available to augment any of these tallies, ranging from dose conversion factors to any cross section defined for ENDF/B-VII (Hendricks and Johnson 2008).

\section{Model validation}

MCNPX code is used to design a model for PWR assembly (Lattice-1) as shown in Fig. 2. This model is fueled with $\mathrm{UO}_{2}$ with enrichment $4.21 \mathrm{wt} \%$ to validate MCNPX calculations. The output results are compared with a previously published data. A variation of the infinity multiplication factor $K_{\text {inf }}$ at different Effective Full Power per Day (EFPD) is compared with that obtained by (Fridman and Kliem 2011) as shown in Fig. 3. The comparison process shows that there is a good agreement between both curves. The small difference in the $\mathrm{K}_{\text {inf }}$ values is due to the type of the cross-section used. The output results of the MCNPX model are more accurate as the cross-section library used is more evolved.

\section{Results and discussion}

The PWR fuel assembly containing typical loadings of gadolinia has been analyzed to investigate their neutronic effects on PWR nuclear fuel (Galahom 2016). Fig. 4 illustrates a horizontal cross section MCNPX computer model of PWR assembly (Lattice-2) fueled with uranium dioxide in addition to IBA rods. Due to the symmetry of PWR assemblies, only one assembly is used to simulate its neutronic characteristics. Table 2 illustrates the fuel composition of the two lattices. The fuel Lattice-1 is fueled with uranium dioxide while the Lattice- 2 is fueled with $\mathrm{UO}_{2}$ in addition to IBAs rods. The IBA rods in the lattice-2 are filled with $\left(\mathrm{UO}_{2}+\mathrm{Gd}_{2} \mathrm{O}_{3}\right.$ ) (Yamamoto et al 2002). Different gadolinium isotopes are used as burna-

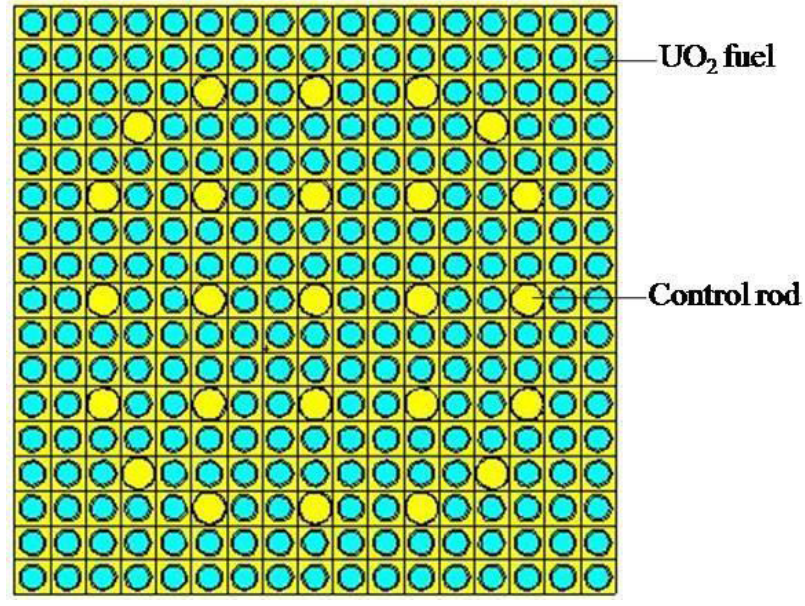

Figure 2. Horizontal cross section MCNPX computer model of PWR assembly fueled with $\mathrm{UO}_{2}$ (Lattice-1).

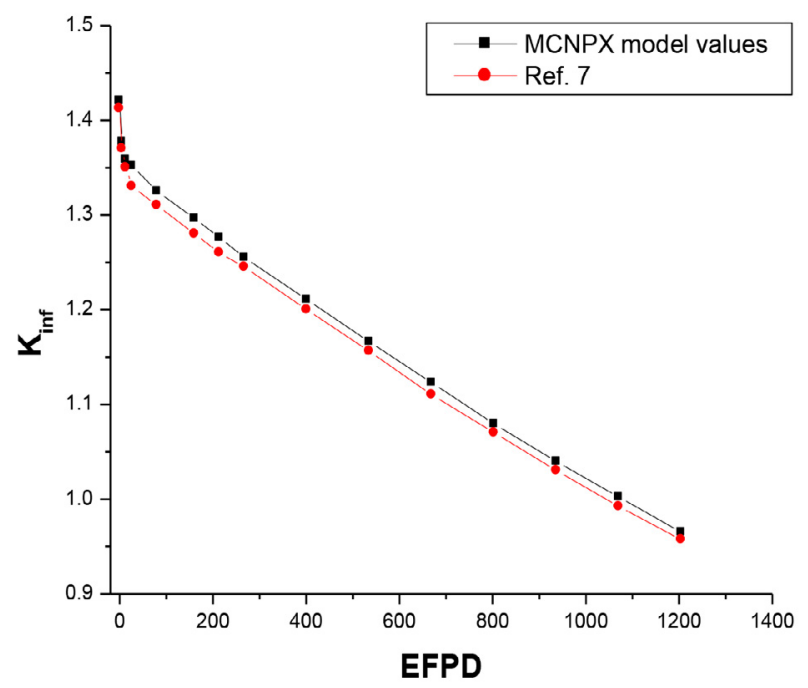

Figure 3. Variation of $K_{\text {inf }}$ with EFPD for $\mathrm{UO}_{2}$ fuel.

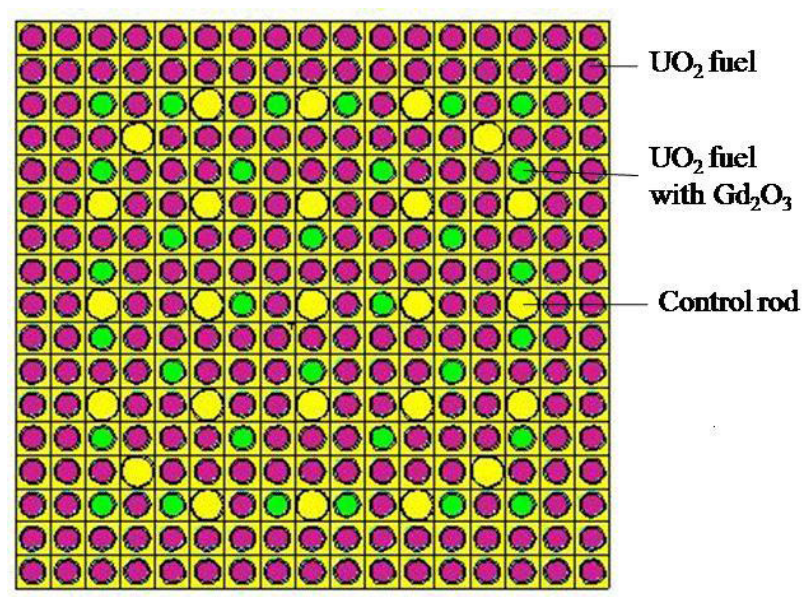

Figure 4. Horizontal cross section MCNPX computer model of PWR assembly fueled with $\left(\mathrm{UO}_{2}+\mathrm{Gd}_{2} \mathrm{O}_{3}\right)$ IBAs (Lattice-2).

ble absorber in the IBA rods. The concentrations of the gadolinium isotopes in the IBA are listed in Table 3.

Fig. 5 illustrates the thermal neutron flux distribution across the lattice- 1 at the beginning of the cycle (BOC). It 
is observed that the thermal neutron flux values increase toward the assembly interior due to the existence of water rods. The thermal neutron flux in the fuel rods around the

Table 2. The fuel composition of the two lattices.

\begin{tabular}{lll}
\hline & Lattice-1 & Lattice-2 \\
\hline Fuel & $\mathrm{UO}_{2}$ & $\mathrm{UO}_{2}$ \\
${ }^{235} \mathrm{U}$ enrichment wt \% & 6.5 & $6.5 \mathrm{wt} \%$ \\
Density $(\mathrm{g} / \mathrm{cc})$ & 10.3 & 10.3 \\
IBA rods & ----- & $\mathrm{UO}_{2}+\mathrm{Gd}_{2} \mathrm{O}_{3}$ \\
$\mathrm{Gd}_{2} \mathrm{O}_{3}$ wt \% & ----- & 10 \\
\hline
\end{tabular}

Table 3. Gadolinium isotopes concentration

\begin{tabular}{lc}
\hline Element & Wt \% \\
\hline${ }^{154} \mathrm{Gd}$ & 2.2 \\
${ }^{155} \mathrm{Gd}$ & 14.8 \\
${ }^{156} \mathrm{Gd}$ & 20.4 \\
${ }^{157} \mathrm{Gd}$ & 15.6 \\
${ }^{158} \mathrm{Gd}$ & 24.8 \\
${ }^{160} \mathrm{Gd}$ & 22.2 \\
\hline
\end{tabular}

\begin{tabular}{|l|l|l|l|l|l|l|l|l|l|l|l|l|l|l|l|l|}
1.89 & 1.91 & 1.94 & 1.98 & 2.04 & 2.05 & 2.08 & 2.05 & 2.04 & 2.05 & 2.02 & 2.02 & 2.01 & 1.96 & 1.97 & 1.94 & 1.90 \\
\hline
\end{tabular} \begin{tabular}{|l|l|l|l|l|l|l|l|l|l|l|l|l|l|l|l|l|l|l|}
\hline 1.91 & 1.93 & 1.96 & 2.06 & 2.12 & 2.24 & 2.15 & 2.15 & 2.21 & 2.15 & 2.15 & 2.26 & 2.19 & 2.08 & 1.99 & 1.94 & 1.92 \\
\hline
\end{tabular} \begin{tabular}{lllllllllllllllllllllll}
1.93 & 1.97 & 2.11 & 2.25 & 2.36 & 3.39 & 2.31 & 2.34 & 3.28 & 2.29 & 2.31 & 3.36 & 2.39 & 2.28 & 2.08 & 1.99 & 1.94 \\
\hline
\end{tabular} \begin{tabular}{lllllllllllllllllllll|l}
\hline 2.00 & 2.00 & 2.25 & 3.39 & 2.42 & 2.40 & 2.26 & 2.23 & 2.31 & 2.22 & 2.26 & 2.35 & 2.43 & 3.28 & 2.30 & 2.06 & 1.97 \\
\hline
\end{tabular} \begin{tabular}{lllllllllllllllllllll|l|l|}
2.02 & 2.09 & 2.31 & 2.38 & 2.34 & 2.40 & 2.25 & 2.23 & 2.31 & 2.23 & 2.26 & 2.37 & 2.35 & 2.43 & 2.38 & 2.15 & 2.04 \\
\hline
\end{tabular} \begin{tabular}{lllllllllllllllllllll|l}
2.02 & 2.23 & 3.35 & 2.36 & 2.35 & 3.40 & 2.37 & 2.36 & 3.40 & 2.34 & 2.33 & 3.42 & 2.40 & 2.37 & 3.37 & 2.25 & 2.09 \\
\hline
\end{tabular} \begin{tabular}{llllllllllllllllllllll}
2.05 & 2.15 & 2.30 & 2.20 & 2.25 & 2.35 & 2.25 & 2.24 & 2.33 & 2.22 & 2.26 & 2.37 & 2.26 & 2.24 & 2.33 & 2.17 & 2.05 \\
\hline
\end{tabular} \begin{tabular}{llllllllllllllllllllll}
2.06 & 2.13 & 2.29 & 2.22 & 2.29 & 2.37 & 2.24 & 2.24 & 2.37 & 2.26 & 2.28 & 2.38 & 2.27 & 2.25 & 2.33 & 2.18 & 2.07 \\
\hline
\end{tabular} \begin{tabular}{llllllllllllllllllllll}
\hline 2.06 & 2.20 & 3.35 & 2.33 & 2.38 & 3.40 & 2.37 & 2.33 & 3.41 & 2.40 & 2.38 & 3.30 & 2.34 & 2.35 & 3.40 & 2.30 & 2.08 \\
\hline
\end{tabular} \begin{tabular}{lllllllllllllllllllllll|}
2.08 & 2.16 & 2.33 & 2.25 & 2.22 & 2.40 & 2.28 & 2.24 & 2.36 & 2.26 & 2.28 & 2.40 & 2.26 & 2.24 & 2.32 & 2.15 & 2.06 \\
\hline
\end{tabular} \begin{tabular}{lllllllllllllllllllll}
2.03 & 2.15 & 2.34 & 2.24 & 2.23 & 2.38 & 2.26 & 2.25 & 2.38 & 2.29 & 2.23 & 2.41 & 2.28 & 2.25 & 2.32 & 2.19 & 2.08 \\
\hline
\end{tabular} \begin{tabular}{|l|l|l|l|l|l|l|l|l|l|l|l|l|l|l|l|l|}
\hline 2.06 & 2.28 & 3.35 & 2.40 & 2.38 & 3.44 & 2.36 & 2.37 & 3.44 & 2.38 & 2.40 & 3.48 & 2.41 & 2.42 & 3.37 & 2.27 & 2.09 \\
\hline
\end{tabular} \begin{tabular}{lllllllllllllllllllllllll}
2.03 & 2.17 & 2.35 & 2.44 & 2.32 & 2.37 & 2.28 & 2.28 & 2.38 & 2.27 & 2.27 & 2.41 & 2.35 & 2.40 & 2.38 & 2.14 & 2.05 \\
\hline
\end{tabular} \begin{tabular}{lllllllllllllllllllll}
1.99 & 2.07 & 2.29 & 3.40 & 2.42 & 2.40 & 2.28 & 2.26 & 2.34 & 2.30 & 2.28 & 2.38 & 2.40 & 3.41 & 2.31 & 2.06 & 2.02 \\
\hline
\end{tabular} \begin{tabular}{llllllllllllllllllllllll}
1.95 & 1.98 & 2.11 & 2.25 & 2.37 & 3.36 & 2.31 & 2.33 & 3.38 & 2.33 & 2.36 & 3.39 & 2.34 & 2.30 & 2.12 & 1.98 & 1.98 \\
\hline
\end{tabular} \begin{tabular}{l|l|l|l|l|l|l|l|l|l|l|l|l|l|l|l|l|}
\hline 1.92 & 1.97 & 1.99 & 2.07 & 2.12 & 2.23 & 2.17 & 2.13 & 2.23 & 2.17 & 2.15 & 2.26 & 2.17 & 2.08 & 1.99 & 1.94 & 1.94 \\
\hline
\end{tabular} \begin{tabular}{|l|l|l|l|l|l|l|l|l|l|l|l|l|l|l|l|l|}
\hline 1.92 & 1.93 & 1.97 & 1.96 & 2.02 & 2.04 & 2.04 & 2.04 & 2.09 & 2.07 & 2.04 & 2.07 & 2.03 & 2.01 & 1.97 & 1.94 & 1.90 \\
\hline
\end{tabular}

Figure 5. Thermal neutron flux distribution across lattice-1 (values are multiplied by $10^{13} \mathrm{n} / \mathrm{cm}^{2} \mathrm{~s}$ ), at BOC.

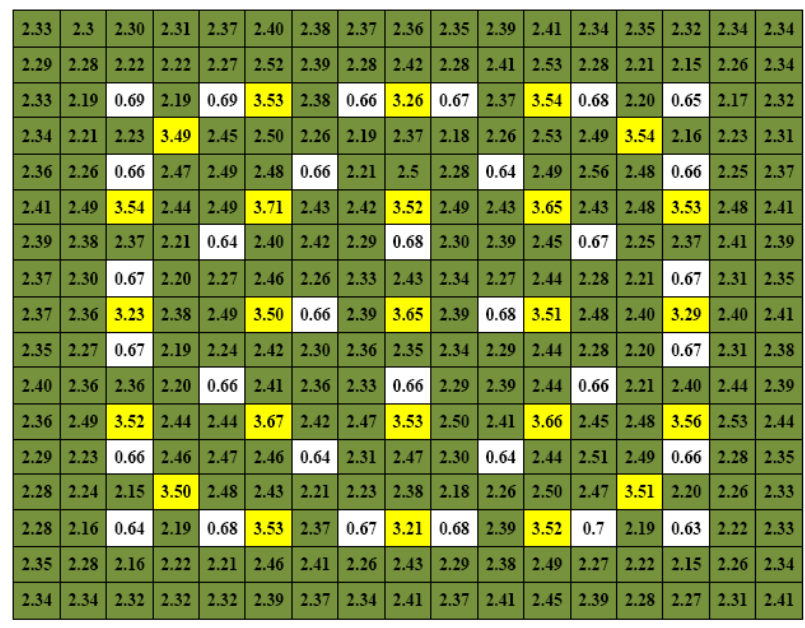

Figure 6. Thermal neutron flux distribution across lattice 2 (values are multiplied by $10^{13} \mathrm{n} / \mathrm{cm}^{2} \mathrm{~s}$ ), at BOC. water rods is larger than that in the assembly periphery as the water convert the fast neutrons resulting from fission process into thermal neutrons. The thermal neutron flux maximize at the water rods. Fig.6. illustrates the thermal neutron flux distribution across lattice- 2 where a burnable absorber material is introduced in the assembly to suppress the high reactivity region. The thermal neutron flux values in the white region are very small compared with other fuel rods where the gadolinium is distributed through the fuel. The thermal neutron flux in lattice-2 distributes more flat than in lattice-ldue to the existences of gadolinium in lattice-2.

Thermal neutrons are responsible for the fission chain reaction in PWR, so the behavior of power is similar to thermal neutron flux. The values of power in the fuel rods around the water tubes are larger than other fuel rods as illustrated in Fig.7. There is no power in the water rods. Fig. 8 illustrates the power distribution across lattice-2. Gadolinium has a large capability to absorb the thermal neutrons, so the neutron spectrum of the IBA $\left(\mathrm{UO}_{2}+\mathrm{G}-\right.$ $\mathrm{d}_{2} \mathrm{O}_{3}$ ) rods is less than $\mathrm{UO}_{2}$ rods. As there is no thermal neutron peak, the power is distributed more flatness in lattice-2 than in lattice-1.

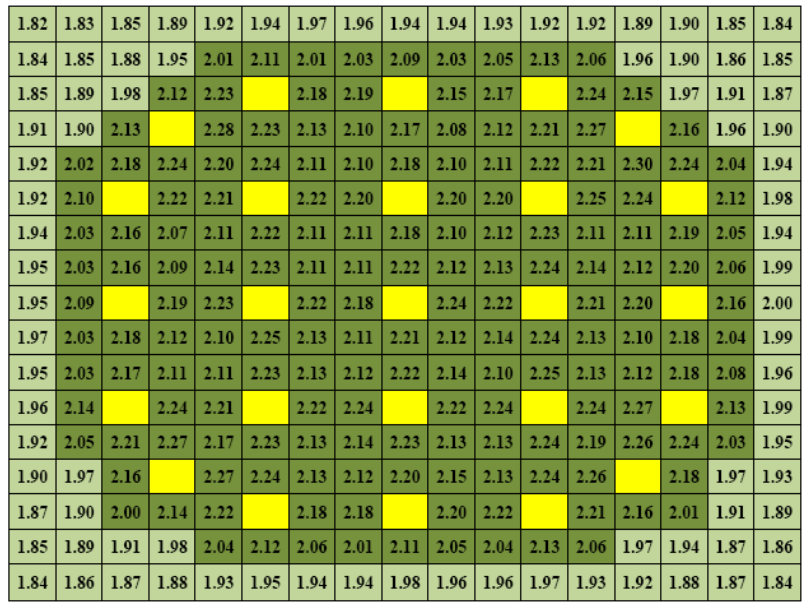

Figure 7. Power distribution across lattice-1 (values are multiplied by $\left.10^{-2} \mathrm{MW}\right)$, at BOC.

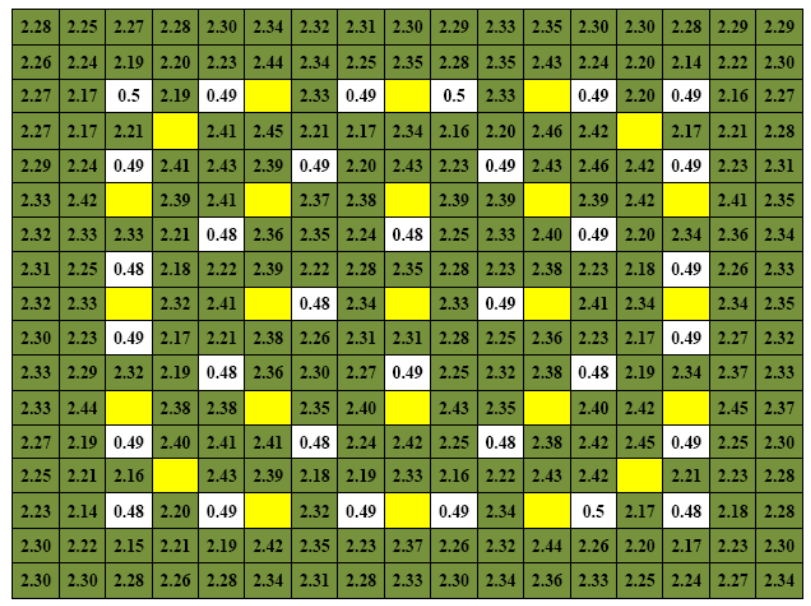

Figure 8. Power distribution across lattice-2 (values are multiplied by $\left.10^{-2} \mathrm{MW}\right)$, at BOC. 
Fig.9 illustrates the $K_{\text {inf }}$ at different Effective Full Power per Day (EFPD) for two lattice type. For PWR assembly fueled without IBAs (lattice-1), the $K_{\text {inf }}$ decreases with EFPD in a nearly linear shape. The $K_{\text {inf }}$ of lattice- 1 decreases dramatically at BOC because of the contributions of ${ }^{135} \mathrm{Xe}$ and ${ }^{149} \mathrm{Sm}$ atoms. All fission products have the ability to absorb neutrons to some extent, and their accumulation in a reactor leads to reduce its multiplication factor. Therefore, the fission product elements are of the greatest importance in thermal reactors

In contrast, for a PWR assembly design that makes significant use of IBAs (lattice-2), the $K_{\text {inf }}$ values in the period from 5 EFPD to 300 EFPD are nearly stable. Starting from $300 \mathrm{EFPD}$, the $K_{\text {inf }}$ value actually increases as the fuel burnup proceeds reach a maximum at a point where the IBA is nearly depleted, and then decreases with EFPD in a nearly linear shape. The existence of $\mathrm{Gd}_{2} \mathrm{O}_{3}$ prevents from more ${ }^{235} \mathrm{U}$ undergoes fission. Therefore, more ${ }^{235} \mathrm{U}$ was consumed in the case of lattice- 1 than in the case of lattice-2 as illustrated in Fig. 10.

Different number of IBA rods had been investigated to select the suitable number of the IBA rods that can be used in the PWR assembly. Fig.11 illustrates the variation of $K_{\text {inf }}$ values with EFPD at different number of IBAs rods. The $K_{i n f}$ values decrease when the number of IBAs

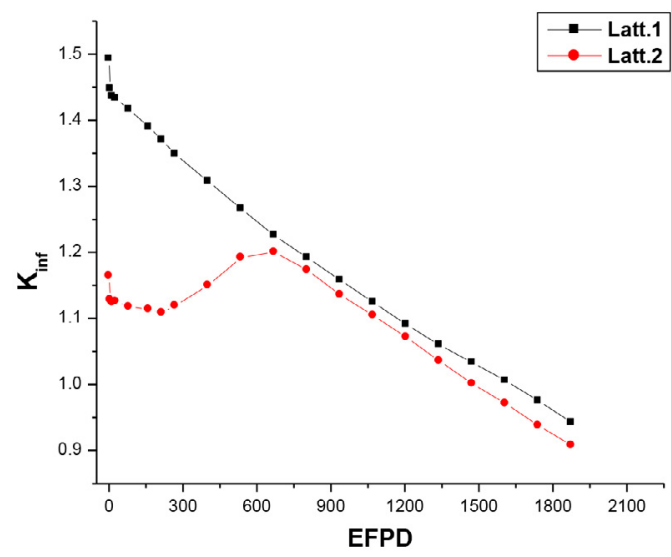

Figure 9. Infinity multiplication factor at different EFPD.

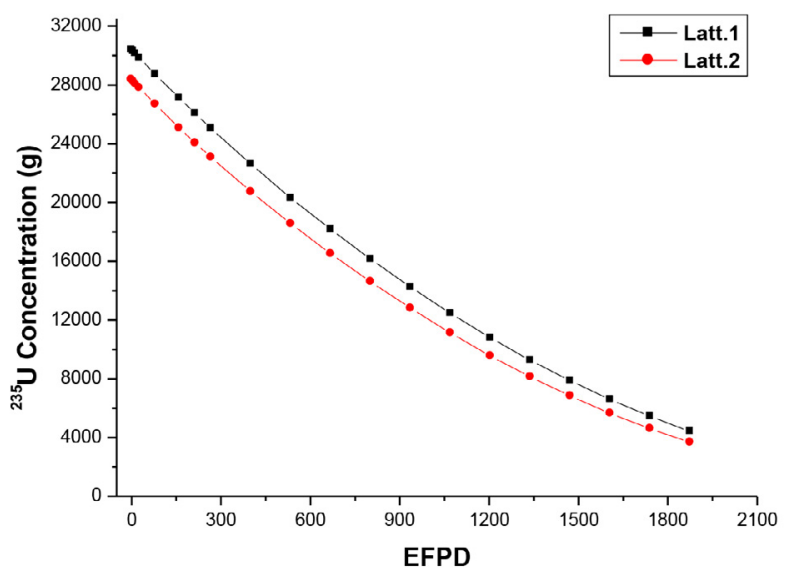

Figure 10. Variation of the ${ }^{235} \mathrm{U}$ concentration with EFPD for the two lattice type. rods increases as in the IBAs rods a part of the $\mathrm{UO}_{2}$ is replaced by $\mathrm{Gd}_{2} \mathrm{O}_{3}$. It is observed that using more than 42 IBA rods in the PWR assembly decreased the $K_{\text {inf }}$ value below the critical state at the BOC.

Both ${ }^{135} \mathrm{Xe}$ and ${ }^{149} \mathrm{Sm}$ are considered the most important fission product poisons whose thermal absorption cross-sections are $2.65 \times 10^{6} \mathrm{~b}$. and $5.85 \times 10^{4} \mathrm{~b}$ respectively. Fig. 12 and Fig. 13 display the ${ }^{135} \mathrm{Xe}$ and ${ }^{149} \mathrm{Sm}$ con-

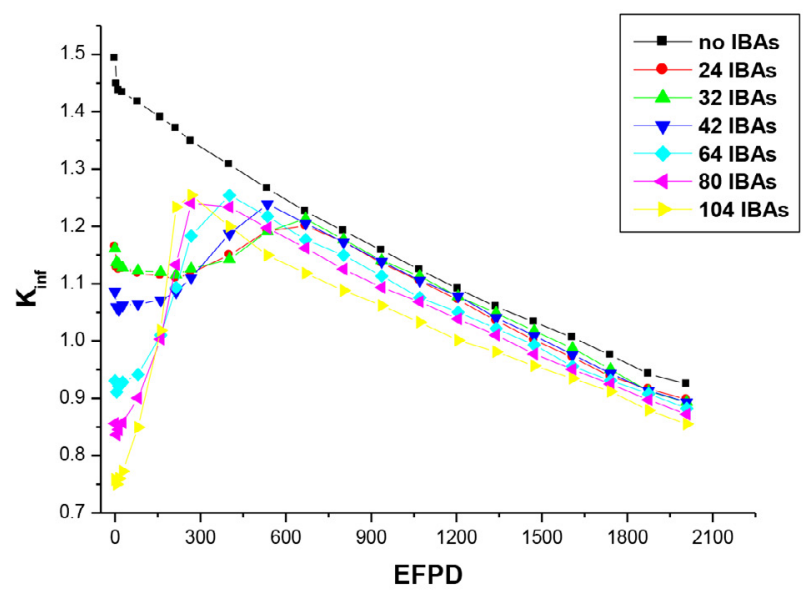

Figure 11. Infinity multiplication factor versus EFPD at different number of IBAs rods.

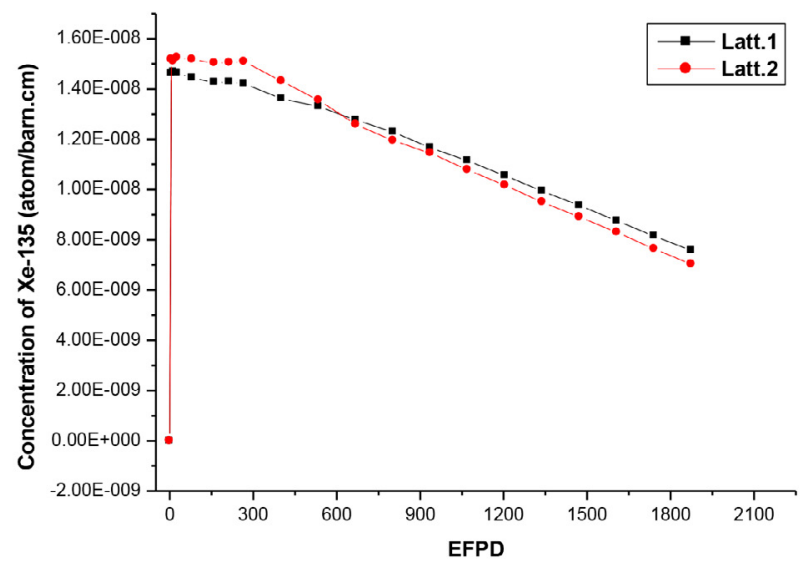

Figure 12. Variation of Xe-135 concentration versus EFPD.

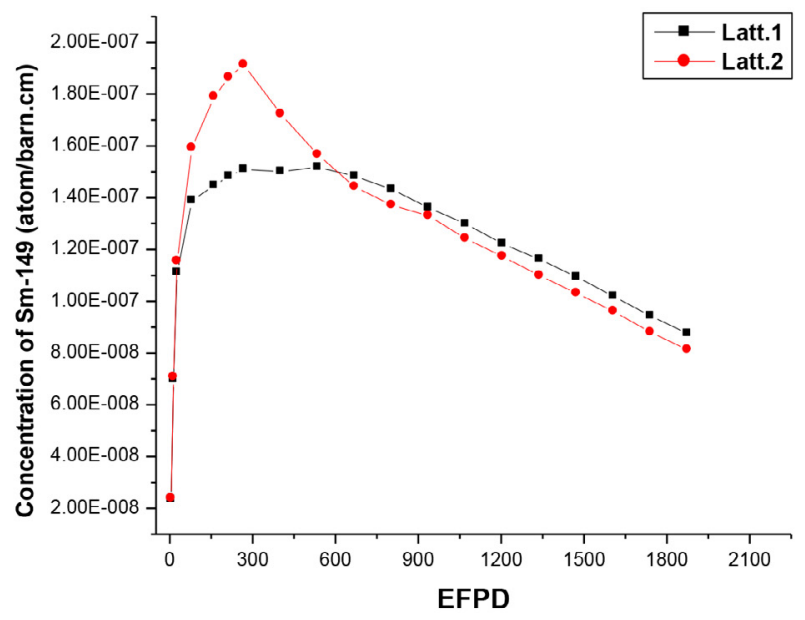

Figure 13. Variation of Sm-149 concentration versus EFPD. 
centration at different EFPD, respectively. The ${ }^{135} \mathrm{Xe}$ and ${ }^{149} \mathrm{Sm}$ concentrations in lattice-2 are larger than in lattice-1 due to the existence of gadolinium. The degradation of gadolinium with burnup contributes to increase the concentration of ${ }^{135} \mathrm{Xe}$ and ${ }^{149} \mathrm{Sm}$.

Fig.14 illustrates the variation of the gadolinium reactivity worth with the EFPD. The reactivity of the reaction in PWR can be calculated by Eq.1 (Costa et al. 2009),

$$
\Delta \rho(\mathrm{pcm})=\left[\left(\mathrm{k}_{2}-\mathrm{k}_{1}\right) /\left(\mathrm{k}_{2} \cdot \mathrm{k}_{1}\right)\right] \cdot 10^{5}
$$

where $\mathrm{pcm}=$ per cent mile, $\mathrm{K}_{2}$ and $\mathrm{K}_{1}$ are the effective multiplication factor with and without the IBAs rods. The presence of the gadolinium has a negative effect on the reactivity of the reaction. The reduction in the negative reactivity with the EFPD is due to the net reduction of the gadolinium isotopes concentrations that are used in the IBAs rods. The negative reactivity decreases with burnup until reach a steady state at which the gadolinium in the IBA rods is nearly depleted. There is a breakdown in the negative value of the reactivity from 240 EFPD to 700 EFPD. This breakdown is due to the change of ${ }^{155} \mathrm{Gd}$ to ${ }^{156} \mathrm{Gd}$ concentration. The gadolinium isotopes have the ability to absorb the thermal neutrons and convert to another isotope.
Therefore, the concentration of ${ }^{155} \mathrm{Gd}$ and ${ }^{157} \mathrm{Gd}$ decreases while the concentration of ${ }^{156} \mathrm{Gd}$ and ${ }^{158} \mathrm{Gd}$ increases with EFPD as illustrated in Fig.15. The importance of ${ }^{155} \mathrm{Gd}$ and ${ }^{157} \mathrm{Gd}$ comes from its high thermal neutron absorption cross-section. Table 4 illustrates the capture cross section of gadolinium isotopes that is used in the IBA rods.

\section{Conclusion}

The present MCNPX model results for $k_{i n f}$ were found in a good agreement with previous published studies. Using of the IBA rods in the PWR assembly suppressed the radial peak power. The radial power distributed more flat in lattice-2 than in lattice-1. Using of gadolinium has a large importance to suppress the high $K_{\text {inf }}$ values at the BOC. The negative reactivity of the gadolinium decreases rabidly due to the fast degradation of ${ }^{155} \mathrm{Gd}$ and ${ }^{157} \mathrm{Gd}$. The suitable IBAs number that can be used in the PWR assembly must not exceed 42 rods. The fission product poisons $\left({ }^{135} \mathrm{Xe}\right.$ and $\left.{ }^{149} \mathrm{Sm}\right)$ affect on the multiplication factor values at the BOC. The presence of $\mathrm{Gd}_{2} \mathrm{O}_{3}$ in the assembly increases the production of ${ }^{135} \mathrm{Xe}$ and ${ }^{149} \mathrm{Sm}$ atoms.

Table 4. The capture cross section of the gadolinium isotopes (Nichols et al. 2008)

\begin{tabular}{cc}
\hline Element & Capture cross sections (barn) \\
\hline${ }^{154} \mathrm{Gd}$ & $85 \pm 12$ \\
${ }^{155} \mathrm{Gd}$ & $60900 \pm 500$ \\
${ }^{156} \mathrm{Gd}$ & $254000 \pm 815$ \\
${ }^{157} \mathrm{Gd}$ & $2.2 \pm 0.2$ \\
${ }^{158} \mathrm{Gd}$ & $1.4 \pm 0.3$ \\
\hline
\end{tabular}

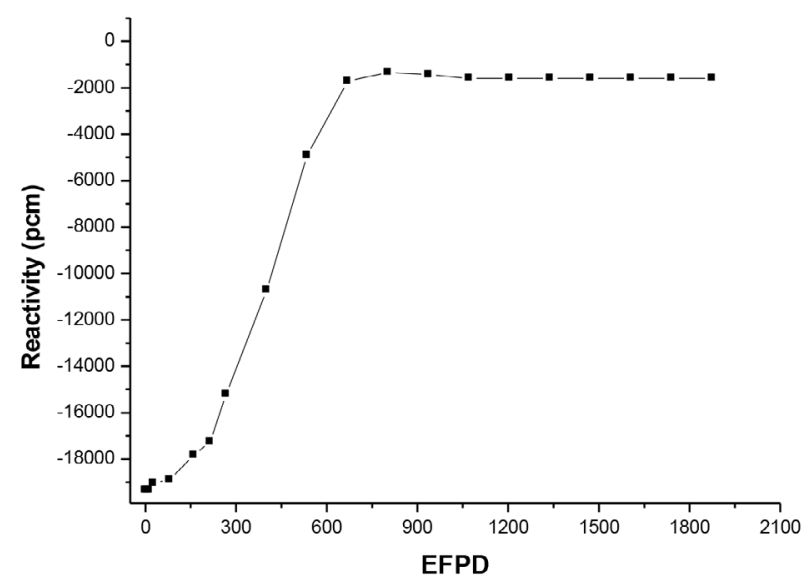

Figure 14. Variation of the gadolinium reactivity worth with EFPD for lattice-2.

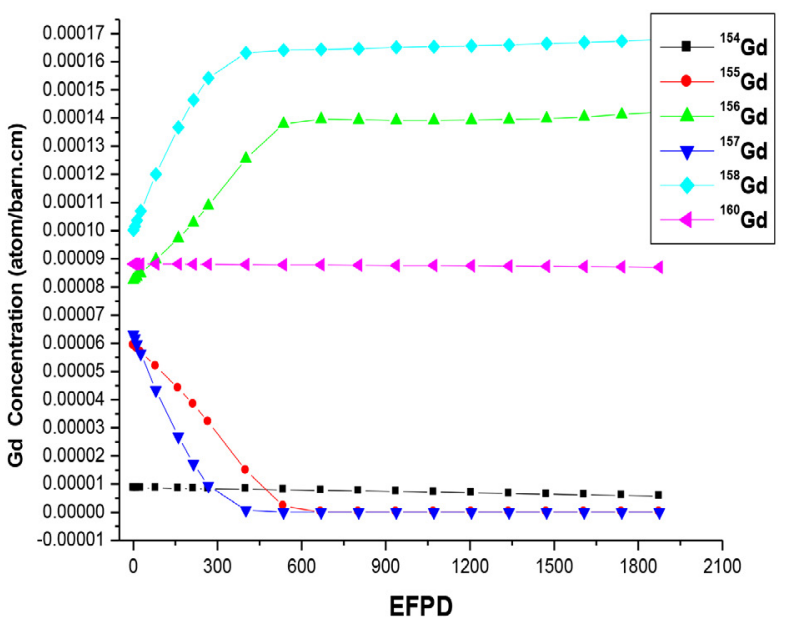

Figure 15. Variation of the gadolinium isotopes concentration with EFPD. 


\section{References}

- Costa AL, Pereira C, Veloso MA, Silva CAM (2009). A neutronic evaluation of the $(\mathrm{Pu}-\mathrm{U})$ and $(\mathrm{Am}-\mathrm{Pu}-\mathrm{U})$ insertion in a typical fuel of Angra-I. Annals of Nuclear Energy. 36: 1-6. https://doi. org/10.1016/j.anucene.2008.11.006

- Fridman E, Kliem S (2011) Pu recycling in a full Th-MOX PWR core. Part I: Steady state analysis. Nuclear Engineering and Design. 241: 193-202. https://doi.org/10.1016/j.nucengdes.2010.10.036

- Galahom AA, Bashter II, Aziz M (2015) Neutronic analysis and validation of boiling water reactor core designed by MCNPX code. Annals of Nuclear Energy 76: 461-468. https://doi.org/10.1016/j. anucene.2014.10.025

- Galahom AA (2016) Investigation of different burnable absorbers effects on the Neutronic characteristics of PWR assembly. Annals of Nuclear Energy 94: 22-31. https://doi.org/10.1016/j.anucene.2016.02.025

- Hendricks JS, Johnson MW (2008) LA-UR-08-1808. MCNPX 26F Extensions. Los Alamos National Lab.

- Huda MQ, Rahman MM, Imtiaz MA, Nguyen KC (2011) Design studies of a typical PWR core using advanced computational tools and techniques. Annals of Nuclear Energy, 38: 1939-1949.
- Karahan A (2010). Possible design improvements and a high power density fuel design for integral type small modular pressurized water reactors. Nuclear Engineering and Design. 240: 2812-2819. https:// doi.org/10.1016/j.nucengdes.2010.06.026

- Nichols AL, Aldama DL, Verpelli M (2008) Handbook of nuclear data for safeguards. International Atomic Energy Agency. INDC-0534.

- O’Leary PM, Pitts ML (2000) Effects of Integral Burnable Absorbers on PWR Spent Nuclear Fuel. Transactions of American Nuclear Society. 83.

- Sanders CE, Wagner JC (2002) Study of the Effect of Integral Burnable Absorbers for PWR Burnup Credit. Oak Ridge National Laboratory. NUREG/CR-6760.

- Yahya MS, Kim Y, Chungb CK (2014) A Novel Burnable Absorber Concept for PWR: BigT (Burnable Absorber-Integrated Guide Thimble). Transactions of the Korean Nuclear Society Spring Meeting Jeju, Korea, May 29-30.

- Yamamoto A, Ikehara T, Ito T, Saji E (2002) Benchmark Problem Suite for Reactor Physics Study of LWR Next Generation Fuels. Journal of Nuclear Science and Technology, 39: 8, 900-912. 